\title{
Competência comunicativa e letramento crítico: formação de professores de língua estrangeira para a cidadania e inclusão social
}

\author{
Communicative competence and critical literacy: preparing EFL teachers for citizenship \\ and social inclusion
}

Mellissa Moreira Figueiredo Barbosa Universidade Estadual de Feiras de Santana

Feira de Santana, Bahia, Brasil

Milenna Brun

Universidade Estadual de Feiras de Santana

Feira de Santana, Bahia, Brasil

José Railson da Silva Costa

Universidade Estadual de Feiras de Santana

Feira de Santana, Bahia, Brasil

\begin{abstract}
Resumo: Este trabalho apresenta o processo de desenvolvimento da competência comunicativa e das práticas de letramento crítico no âmbito das turmas de língua inglesa do Programa de Extensão Portal: ensinoaprendizagem de línguas para a cidadania, inclusão social e diálogo multi e intercultural, na Universidade Estadual de Feira de Santana, em 2016. O artigo aborda ainda o percurso de elaboração de dois módulos didáticos autênticos que servem como suporte didático para o curso. Durante o curso, os aprendizes buscam desenvolver a competência comunicativa, ao passo que despertando a consciência sobre diversos temas instigantes debatidos em sala de aula e expandindo sua capacidade de pensar de forma crítica e reflexiva sobre as relações individuais e coletivas em diversas dimensões. Focado no desenvolvimento de múltiplas competências e baseado nos princípios do trabalho cooperativo e colaborativo no processo de ensinoaprendizagem de língua inglesa, o Programa Portal busca complementar a formação didática dos graduandos em Letras e oferecer oportunidades de aprendizagem de línguas estrangeiras para as comunidades interna e externa. No eixo formativo, o Programa Portal possibilita que os bolsistas de extensão desenvolvam suas competências didáticas teórico-reflexivas, através da leitura e discussão de textos vinculados ao grupo de pesquisa ELCE, e suas habilidades docentes, através do planejamento das aulas e elaboração de material didático. No eixo inclusivo-social, oferece oportunidades de aprendizagem de línguas com base na partilha de conhecimentos, na interação entre os parceiros de turma, no empoderamento pessoal e no desenvolvimento da autonomia e da cidadania para que os aprendizes ocupem espaços em suas comunidades e fora delas, estabelecendo um diálogo com indivíduos de diferentes contextos e origens.
\end{abstract}

*Bolsista Programa ]'ortal, Gra uanda em Licenciatura em Letras com Inglês, UEFS. E-mail: mellissabarbosa@hotmail.com.

**Professora Titular Língua Inglesa na Universidade Estadual de Feira de Santana, Dra. Didactologia de Línguas e Culturas Estrangeiras, Université de la Sorbonne Nouvelle, Paris 3, Coordenadora Língua Inglesa Programa Portal. E-mail: milennab@uefs.br.

***Bolsista Programa Portal, Graduando em Licenciatura em Letras com Inglês, UEFS. E-mail: railson-costa3@hotmail.com. 
Palavras-chave: Competência Comunicativa. Letramento Crítico. Material Didático Autêntico. Ensino de língua inglesa.

\begin{abstract}
This paper presents the process of the communicative competence development and its practices in critical literacy in the English classes of Portal Extension Program: teaching and learning of languages for citizenship, social inclusion and multi and intercultural dialogue at the State University of Feira de Santana in 2016 and also the development of two didactic modules which were used as a support material to the course. During the language course, learners seek to develop the communicative competence in the same way they arouse consciousness about several themes discussed in the classroom and expand their capacity to think critically and reflexively about their individual and collective relationships in several dimensions. Focused on the development of multiple competences and based on the principles of cooperative and collaborative work in the English language teaching-learning process, the Portal Program aims to complement the training of English graduate students and to provide foreign language learning opportunities for the internal and external communities. The formative axis of the Portal Program enables the trainees to develop both their theoreticalreflective teaching skills through reading and discussion of texts linked to ELCE research group and also their teaching skills by lesson planning and teaching materials preparation. Its inclusive social-axis offers languagelearning opportunities based on knowledge sharing, interaction, personal empowerment and autonomy and citizenship development to occupy spaces inside and outside their communities while establishing a dialogue with individuals from different contexts and backgrounds.
\end{abstract}

Keywords: Communicative competence. Critical literacy. Authentic teaching material. English language teaching.

\title{
1 INTRODUÇÃO
}

Este artigo propõe uma análise sobre o letramento crítico (doravante LC) nas aulas de língua inglesa (doravante LI) de um Programa de Extensão da Universidade Estadual de Feira de Santana, que se propõe a desenvolver a competência comunicativa através de um trabalho cooperativo e colaborativo. Esse método foi proposto por Johnson e Johnson (1984), após a realização de pesquisas de desempenho em grupo, com o intuito de propiciar aos participantes uma aprendizagem mais dinâmica, interativa e estimuladora do pensamento crítico. Essa prática didática propõe que os professores e alunos construam o conhecimento coletivamente, de forma que haja interação entre as partes, fugindo da forma tradicional de ensino, na qual o professor é o reprodutor do conhecimento e o aprendiz apenas um receptor. Atualmente, para funcionar plenamente nas sociedades modernas, dinâmicas e globalizadas, é essencial que os indivíduos estejam aptos a pensar criticamente a respeito das formas de organização sociais, políticas e econômicas. A fim de contribuir para a comunidade na qual estão inseridos, os indivíduos precisam desenvolver o letramento crítico e serem capazes de interpretar contextos, potencializando assim sua capacidade de leitura de mundo.

O letramento crítico, no caso específico do ensino-aprendizagem de Língua Inglesa, proporciona uma oportunidade de entrar em contato com outras realidades, outros modos de se pensar cultura, o acesso à tecnologia e possibilidades de vivenciar novas descobertas a partir da inserção do aprendiz em variados contextos socioculturais. Segundo os PCN (1998), os estudantes devem ser capazes de se posicionar criticamente ao transitar em diversos contextos, estando aptos a dialogar e mediar conflitos de forma que haja respeito e tolerância com os outros indivíduos de diferentes situações econômicas, sociais, políticas e culturais. Com o desenvolvimento das práticas de LC em 
sala de aula, os aprendizes são empoderados para exercer sua cidadania com autonomia e liberdade, de modo a provocarem mudanças locais e globais, desde as relações em sala de aula até as relações com o mundo exterior.

O objetivo maior das aulas de Língua Inglesa é desenvolver a competência comunicativa dos aprendizes. Ao falarmos de competência comunicativa, precisamos voltar ao conceito de língua e pensar que língua não é somente "[...] um sistema de signos distintos correspondentes a ideias distintas" (SAUSSURE,1969, p.18). A língua para o falante não é uma forma normativa, ela está em constante movimento e se adequa aos diferentes contextos sociais. Dell Hymes (1972) foi o primeiro teórico a cunhar o termo competência comunicativa, enfatizando o enfoque sociolinguístico para a comunicação e destacando os fatores sociais que são extremamente importantes para uma comunicação efetiva.

Em sala de aula, as práticas de letramento crítico e o desenvolvimento da competência comunicativa estão entrelaçados na medida em que os estudantes discutem e debatem temas provocadores e atuais em LI que os possibilitam conhecer outras dimensões sociais e culturais. Para tanto, o material didático desenvolvido no Programa Portal se constitui de textos autênticos orais e escritos de diversos gêneros discursivos. Visa-se assim ao desenvolvimento de práticas sociais discursivas que intensifiquem o engajamento dos participantes no processo de ensino-aprendizagem e a reflexão sobre a importância da aprendizagem de línguas no contexto humano atual.

Bianca Schubert (2010) indica dois aspectos ou fatores incentivadores para a intensificação do uso de materiais autênticos como suporte didático nas aulas de línguasculturas estrangeiras: o acesso amplo às tecnologias de comunicação e informação e a busca de autonomia na aprendizagem.

Embora existam variadas perspectivas sobre a autenticidade do texto, neste trabalho consideramos autênticos aqueles textos que apresentam uma qualidade comunicativa e não foram originalmente elaborados com fins pedagógicos.

O ensino de línguas-culturas no Programa Portal não visa à mera repetição e decodificação mecânica de estruturas. Busca, pelo contrário, aprendizagens significativas para o aprendiz. Nesse sentido, propõe um trabalho em sintonia com as diretrizes nacionais para o ensino de línguas estrangeiras, tentando (1) capacitar os alunos a perceberem que vivem em um mundo plurilíngue e pluricultural, (2) possibilitar que os alunos tenham acesso aos bens culturais da humanidade, e (3) apresentar as produções socioculturais de diversos grupos humanos a fim de que os alunos estejam habilitados para valorizar a diversidade, assumindo uma posição de abertura e criticidade.

\section{COMPETÊNCIA COMUNICATIVA E LETRAMENTO CRÍTICO NO PROCESSO DE ENSINO-APRENDIZAGEM COOPERATIVO- COLABORATIVO}

O conceito de competência foi introduzido por Chomsky em 1965 ao tratar a língua como conhecimento gramatical inato ao ser humano, levando em conta somente os aspectos linguísticos e não mencionando os aspectos sociais da língua, defendendo que a 
competência é algo somente biológico. Segundo Dell Hymes (1972), o conceito de competência comunicativa transcende a teoria formalista de Chomsky. O autor explicita sua posição afirmando que "há vários setores de competência, um dos quais é o gramatical” (HYMES, 1972, p. 281). Para Hymes (1972), a competência comunicativa é muito mais do que somente a gramática, é a interação sociocultural entre os falantes, os fatores psicológicos e os estados emocionais. Hymes (1976) afirma que a língua precisa estar associada ao contexto, pois o fator social é extremamente importante para o seu desenvolvimento. Assim, o termo Competência Comunicativa foi cunhado pelo autor ao comtemplar os conhecimentos "linguísticos, psicolinguísticos, sociolinguísticos e pragmáticos além das habilidades que os falantes devem desenvolver a fim de comunicarse através da língua" (ORTIZ, 2015, p. 242).

Nesse contexto, na década seguinte, Canale e Swain (1980) e Canale (1983), dando continuidade às ideias de Hymes, propuseram que a competência comunicativa deveria englobar as competências estratégica e discursiva, além da linguística ou gramatical e da sociolinguística já propostas pelo referido teórico. Assim, se os aprendizes entrassem em contato com todas essas dimensões, eles poderiam desenvolver efetivamente sua competência comunicativa. Em 2007, numa revisão de seu modelo proposto em 1995 , Celce-Murcia afirma que as competências que constituem a competência comunicativa são as competências discursiva, sociocultural, linguística, formulaica e interacional, essas duas últimas ressaltando a fluidez da língua em relação a uma visão sistemática e a interação entre os sujeitos.

Nessa perspectiva, o modelo de Competência Comunicativa que se desenvolve no contexto do Programa Portal partiu dos estudos de todos esses autores (Hymes 1972; Canale \& Swain, 1980; Canale, 1983, Celce-Murcia, 2007), com alterações advindas dos estudos multi e interculturais. Logo, nosso modelo inclui: competência discursiva, competência pragmática, competência linguística, competência sociolinguística, competência intercultural, competência afetiva e competência estratégica de aprendizagem e de comunicação ao conceituar competência comunicativa como a capacidade que o indivíduo tem de mobilizar todos os recursos, os conhecimentos, os saberes, as vivências, as crenças e as atitudes para agir e interagir de forma comunicativa e adequada numa determinada situação de comunicação.

Diante dessas considerações, trazemos essa reflexão para o contexto de sala de aula, ao compreender que, para desenvolver a competência comunicativa e todas as competências que a constituem, é necessário que os sujeitos aprendentes sejam expostos a múltiplos discursos através de diversos gêneros textuais, a fim de formar cidadãos críticos, políticos e reflexivos. Tais discursos são manifestados nas práticas sociais através da interação entre os indivíduos. As atividades empreendidas em sala de aula fundamentam-se no desenvolvimento da competência comunicativa, na formação reflexiva e no processo de ensino-aprendizagem cooperativo-colaborativo. Segundo Johnson \& Johnson (1984), esse modo de funcionamento tende a promover o pensamento crítico e a interação dos indivíduos intensificando a interação mútua entre alunos e professores, que não funcionam apenas como tradicionais reprodutores de 
conhecimento, mas engajam-se ativa e reflexivamente no processo de ensinoaprendizagem.

Isso faz crer que a aprendizagem de uma língua estrangeira não deve estar desassociada de ideologias e dos contextos político, cultural e social. Para tanto, as pesquisas sobre os novos letramentos vêm surgindo no mundo desde o final dos anos 70 , quando houve uma mudança da visão tecnicista do letramento para a visão social ligada ao contexto sociocultural dos sujeitos. Para Soares (1998, p.72), letramento "[...] é o que as pessoas fazem com as habilidades de leitura e de escrita, em um contexto específico, e como essas habilidades se relacionam com as necessidades, valores e práticas sociais". Kleiman (2001, p.11) fomenta essa visão ao definir letramento como “[...] práticas sociais cujos modos específicos de funcionamento tem implicações importantes para as formas pelas quais os sujeitos envolvidos nessas práticas constroem relações de identidade e de poder”. Logo, ao compreender que a língua é discurso e é construída a partir dos sentidos advindos do contexto sociocultural dos sujeitos, faz-se necessário o uso das práticas de letramento para que a leitura e a escrita sejam transcendidas e alcancem o desenvolvimento das estâncias crítica e reflexiva da aprendizagem de línguas.

Dessa forma, de acordo com os PCN,

[...] quando um sujeito interage verbalmente com outro, o discurso se organiza a partir das finalidades e intenções do locutor, dos conhecimentos que acredita que o interlocutor possua sobre o assunto, do que supõe serem suas opiniões e convicções, simpatias e antipatias, da relação de afinidade e do grau de familiaridade que têm, da posição social e hierárquica que ocupam. Isso tudo determina as escolhas do gênero no qual o discurso se realizará, dos procedimentos de estruturação e da seleção de recursos linguísticos. (PCN, 1998, p. 21).

Com o intuito de utilizar as práticas de letramento em sala de aula, propomos que haja um foco nas práticas de letramento crítico no ambiente de ensino-aprendizagem de língua inglesa ao entrar em contato com diversos gêneros discursivos, pois os estudantes precisam se empoderar e desenvolver sua consciência crítica para questionar e transitar em diversas situações sociais. Segundo o Núcleo de Assessoria Pedagógica da Universidade do Paraná (2006), o Letramento Crítico é “[...] uma prática educacional que tem como foco a relação entre língua e visões de mundo, práticas sociais, poder, identidade, cidadania, relações interculturais e assuntos globais/locais". Nesse contexto, o processo de ensino-aprendizagem de uma língua estrangeira passa a ser uma oportunidade para construir diferentes realidades e concepções sobre o mundo, ao propiciar aos sujeitos aprendentes a chance de analisar, de forma crítica e reflexiva, diversos contextos socioculturais, pois, ao serem letrados criticamente, terão autonomia para enxergar os sentidos além do texto e expor o que pensam.

Dentro do Programa Portal, todos esses aspectos elencados são englobados no material didático e, consequentemente, nas aulas, para alicerçar as práticas de letramento crítico. Os aprendizes têm acesso a diversos saberes linguístico-culturais ao estudar temas estimulantes, através dos quais eles questionam e discutem conhecimentos, valores, crenças e diferentes perspectivas sobre cada tópico. O material didático autêntico utilizado 
no curso expõe questões sociopolíticas existentes no mundo globalizado e traz à tona interações sociais reais. Segundo Lee (1995, p. 324 apud Schubert, 2010, p. 20),

Um texto é considerado autêntico se ele não foi escrito com propósitos pedagógicos (i.e. não para ilustrar pontos específicos de uma língua), mas com um propósito comunicativo da vida real, onde o escritor tem uma determinada mensagem para passar para o leitor.

Os textos autênticos advindos de jornais, revistas, redes sociais, entrevistas e variados sites se diferem dos textos que frequentemente são usados pelos professores em aulas de língua estrangeira. Muitos desses textos utilizados têm a finalidade de tratar de um tópico gramatical específico e são criados especificamente para aquela necessidade, não refletindo assim a realidade do discurso com variações linguísticas, expressões idiomáticas, entre outros aspectos. Nos textos autênticos, não há um controle dos recursos linguísticos presentes, e os aprendizes estão expostos à língua de fato.

Em consequência disso, para desenvolver a competência comunicativa dos aprendizes, é importante que eles tenham contato com diversas situações comunicativas através de materiais autênticos. Dessa maneira, os estudantes podem fazer uma viagem pelo mundo ao serem expostos a múltiplas perspectivas do tópico que está sendo trabalhado em sala de aula e podem desenvolver a consciência crítica sobre diversos contextos e questões que os envolvem. Assim sendo, os aprendizes têm a oportunidade de tornarem-se cidadãos autônomos, que conseguem enxergar as diversas ideologias contidas nos textos de diversos gêneros, orais e escritos, os quais estão englobados no material didático. Logo, isso faz crer que a língua estrangeira com que o aprendiz está em contato na sala de aula é a língua que é usada nas situações comunicativas reais. Portanto, há uma imersão verdadeira na língua-alvo mesmo não estando num país que a tem como língua oficial. Desse modo, aprender uma língua estrangeira é perceber que é possível atuar nas diversas práticas sociais, estar aberto ao novo, questionar, pensar de forma independente e analisar criticamente as construções de sentidos que estão a nossa volta.

\section{PISTAS METOdOLÓgICAS NA FORMAÇÃO DE PROFESSORES DE LÍNGUA INGLESA}

O Programa Portal: ensino-aprendizagem de linguas modernas para a cidadania, inclusão social, diálogo multi e intercultural é um Programa de Extensão fundado em 2003, que tem por objetivo oferecer oportunidades de desenvolvimento da competência comunicativa em línguas estrangeiras, de forma gratuita, a estudantes da rede pública de ensino que tenham mais de 14 anos de idade, ou a egressos dessas instituições e que não estejam matriculados em escolas particulares. O Programa Portal visa também contribuir para a formação profissional de estudantes dos cursos de Licenciatura em Letras Estrangeiras da Universidade Estadual de Feira de Santana. Uma das atividades principais do Programa é a oferta de cursos de línguas estrangeiras, como inglês, espanhol e francês e português como língua materna e estrangeira. Esses cursos de línguas têm como principal objetivo o desenvolvimento da competência comunicativa dos sujeitos aprendentes. Para a 
realização dessas atividades, o Programa Portal conta com uma equipe de 13 membros entre bolsistas, voluntários e coordenadores. Todas as atividades desenvolvidas em sala de aula visam englobar também o desenvolvimento de múltiplas competências tais como: competência discursiva, competência pragmática, competência linguística, competência sociolinguística, competência intercultural, competência estratégica de aprendizagem e de comunicação.

As aulas são realizadas no campus universitário, em salas de aulas que contam com o suporte de materiais como projetores, notebooks e aparelhos de som, possibilitando a contemplação de todas as habilidades necessárias para o desenvolvimento das competências dos aprendizes. Dessa forma, as atividades acontecem sempre internamente, proporcionando um ponto de intersecção entre o meio acadêmico e os estudantes de escola pública, o que facilita também o apoio e o monitoramento da realização das atividades por parte da Coordenação do programa.

A metodologia desenvolvida no Programa Portal é reflexiva e contempla algumas etapas de suma importância para a realização dos objetivos:

1.Seleção e formação do bolsista do Programa Portal, a partir das discussões e das leituras de referenciais teóricos sobre competência comunicativa e crenças dos professores e alunos de língua inglesa;

2. Participação em reuniões semanais para dialogar a respeito dos referenciais lidos, apresentar propostas para elaboração do material didático e dos planos de aula, e participar da formação necessária sobre a metodologia do programa dentro dos parâmetros preestabelecidos pelo mesmo; os bolsistas do programa, que são professores em formação, discutem textos sobre educação para as línguas e culturas estrangeiras nas reuniões internas e também nos encontros do Grupo de Pesquisa ELCE (Educação para as línguas e culturas estrangeiras);

3. Oferta pública e gratuita dos cursos semestrais através de divulgação em mídias digitais e de forma presencial;

4. Seleção dos estudantes por meio de sorteio eletrônico e chamadas públicas para a inscrição;

5. Acompanhamento de aulas ministradas por outro bolsista mais; e, nos casos de bolsistas novatos e menos experientes, sob a supervisão de um professor coordenador;

6. Elaboração de materiais didáticos, que serão utilizados em sala de aula, organizados na perspectiva dos referenciais lidos e debatidos durante as reuniões pedagógicas com os coordenadores do programa;

7. Cursos de 45h ministrados pelo bolsista de extensão do Programa Portal, a partir das metodologias estudadas nas reuniões pedagógicas;

8. Planejamento de seminários do Programa Portal, a fim de apresentar à comunidade acadêmica a análise e os resultados das atividades desenvolvidas durante o período letivo de desenvolvimento dos cursos.

O material didático elaborado no âmbito do Programa Portal propõe abarcar todas essas competências para que os estudantes se tornem falantes competentes, sujeitos conscientes sobre diversas realidades e cidadãos críticos. Para tanto, dois módulos didáticos foram elaborados a fim de abranger as 30 aulas previstas num curso de carga 
horária de 45 horas, dividindo-se em 12 temas instigantes como gênero e sexualidade, família e relacionamentos, racismo, drogas, entre outros. Esses temas foram escolhidos pelos alunos bolsistas com o intuito de promover discussões, debates e desenvolver o senso crítico dos aprendizes.

Para cada tema, textos autênticos de diversos gêneros foram cuidadosamente selecionados para garantir a conexão com todas as competências propostas pelo Programa. A fim de propor a máxima exposição a diferentes perspectivas advindas de múltiplas fontes, como vídeos de diversas partes do mundo, filmes, séries de TV, textos jornalísticos, textos de blogs, propagandas, charges e mapas foram utilizados nas atividades propostas. Desse modo, os estudantes puderam desenvolver todas as competências propostas de forma contextualizada e através de um processo de aprendizagem no qual eles discutiram assuntos globais ao construir novas identidades, ao ampliar suas visões de mundo e ao analisar de forma crítica e reflexiva tópicos que fazem parte de suas realidades.

O planejamento e toda a composição do material didático foram desempenhados por 3 bolsistas e voluntários da disciplina Língua Inglesa, com supervisão da Coordenação de área e da Coordenação geral do Programa, através da realização de reuniões entre todos os envolvidos no projeto, com o objetivo de produzir, socializar e refletir durante o processo criativo e idealizador de todo o suporte didático. Essas reuniões aconteceram no âmbito do Programa Portal desde o primeiro semestre de 2016, anterior ao início das aulas do curso de Inglês Básico 1, até o fím do curso no final desse mesmo ano.

Nesse contexto, para cobrir uma carga horária de 45h, 30 planos foram elaborados, sendo que as aulas, com duração de $1 \mathrm{~h} 30 \mathrm{~min}$ cada uma, aconteceram duas vezes por semana. Cada unidade organizada refere-se a duas aulas, ou seja, dois planos de aula. Em cada aula, o material didático foi estruturado para que os estudantes fossem capazes de desenvolver suas habilidades oral, escrita, auditiva e leitora. Logo, vídeos autênticos estão referenciados e inseridos nas atividades propostas, a fim de que os estudantes entrem em contato com a língua como ela realmente é ao redor do mundo, ao abordar o tema estudado. Textos de jornais, revistas e blogs advindos de múltiplas culturas e pontos de vistas foram criteriosamente escolhidos para estarem relacionados tanto ao tema e aos outros elementos do material quanto ao nível de língua dos estudantes. Além disso, pequenas composições escritas foram propostas para que os aprendizes pudessem expressar o que conseguiram mobilizar naquela aula sobre aquele tema.

Depois de estudarem e debaterem alguns temas durante 12 horas/aulas, os estudantes realizaram duas avaliações do processo de aprendizagem, uma na metade do curso e outra no final, a fim de verificar o desenvolvimento das 4 habilidades linguísticas. Essa é uma forma de analisar o progresso dos sujeitos aprendentes durante o curso e também de refletir sobre as mudanças que podem ser feitas no material didático e no desenvolvimento das aulas, para que o suporte seja mais eficaz e favorável a uma aprendizagem significativa. 


\section{RESULTADOS E IMPACTOS}

O trabalho desenvolvido pela Coordenação, pelos bolsistas e pelos aprendizes de língua inglesa tem apresentado resultados positivos. Os bolsistas menos experientes tiveram a oportunidade de acompanhar outros bolsistas com maior tempo de atuação e absorver a metodologia do programa mais profundamente, não apenas na área de língua inglesa. Os bolsistas de língua inglesa também tiveram a possibilidade de pesquisar novos temas junto à Coordenação nas reuniões semanais, a fim de inseri-los como nas aulas de ensino-aprendizagem de língua inglesa e, consequentemente, na produção do material didático, com o intuito de estimular o pensamento crítico e reflexivo dos aprendizes.

O material didático propiciou a contemplação eficiente da metodologia do Programa Portal, pois as atividades propostas e os respectivos planos de aula foram organizados a partir da competência comunicativa, do trabalho cooperativo-colaborativo e dos temas selecionados. Cada atividade tratou de um tema diferente, e cada tema foi organizado através de dois planos de aula que detalharam a forma como as competências seriam trabalhadas e como o material didático seria utilizado. Desse modo, 30 planos de aula foram realizados, incluindo as revisões e avaliações. A forma como o material didático foi elaborado pelos bolsistas e coordenadores possibilitou que: as sete competências que compõem a competência comunicativa fossem contempladas: a competência discursiva, a pragmática, a linguística, a sociolinguística, a intercultural, a estratégica e, amais recentemente adotada pelo programa, a afetiva. O módulo de atividades do programa está dividido em 2 partes, como já mencionado, pois os 15 primeiros planos foram desenvolvidos até a primeira avaliação oral e escrita, e a partir do $16^{\circ}$ plano de aula, as cópias da segunda parte do módulo de atividades foram distribuídas.

No segundo semestre de 2016, foram formadas 4 turmas do nível básico 1 de língua inglesa, sendo que cada turma compreendia 20 aprendizes. Dessa forma, 80 aprendizes de língua inglesa forma atendidos em um semestre, todos oriundos de escolas públicas, variando entre aprendizes que ainda estão em idade escolar, aprendizes com o ensino médio completo e estudantes de curso superior da própria universidade e de instituições privadas.

As aulas ministradas no Programa Portal contribuíram significativamente para as perspectivas profissionais e acadêmicas dos bolsistas, pois a metodologia do programa está baseada na competência comunicativa e no trabalho cooperativo-colaborativo, apoiados numa visão mais moderna sobre o ensino de línguas. $\mathrm{Na}$ maioria das vezes, o professor em formação de língua inglesa centraliza sua metodologia de ensino nas vertentes estruturalistas, especificamente em ensino apenas de gramática, terminando por excluir as outras possibilidades de ensino-aprendizagem que estão inseridas no trabalho com uma língua estrangeira. Dessa forma, o bolsista pôde capacitar suas habilidades profissionais, explorando metodologias de ensino mais eficazes para proporcionar um bom aprendizado de língua inglesa.

Outro ponto importante que resultou do trabalho realizado no Programa Portal foi a produção científica proveniente das pesquisas realizadas em ensino de língua inglesa a partir da competência comunicativa, possibilitando a produção de relatos de experiências, 
artigos reflexivos sobre linguística aplicada, discussões sobre crenças de alunos e professores no ensino de línguas e produção de banners para apresentar o trabalho desenvolvido pelo programa em outros eventos estaduais e interestaduais. Todos esses fatores podem contribuir para que o bolsista esteja motivado e preparado para continuar as pesquisas na área da linguística aplicada e possa dar segmento à vida acadêmica, podendo almejar, posteriormente, a pós-graduação.

Os aprendizes de língua estrangeira do Programa Portal puderam ter contato com uma nova metodologia de aprendizagem de línguas e tiveram também a oportunidade de debater e se comunicar a partir de temas relevantes da contemporaneidade, utilizando a língua inglesa. Muitos deles nunca haviam se deparado com a metodologia de ensino utilizada no Programa Portal devido ao ensino utilizado nas escolas públicas, que é focado basicamente em gramática. Apesar desse detalhe, eles se adaptaram rapidamente à metodologia por competência comunicativa e começaram a se sentir muito motivados, especialmente pelo fato das aulas serem ministradas, na maior parte do tempo, em língua inglesa.

Todo o processo de planejamento didático também permitiu a seleção de temáticas atuais e instigadoras que mereceram discussões por vezes acaloradas, mas bastante significativas para o desenvolvimento da cidadania (gênero e sexualidade, meio ambiente e sustentabilidade, racismo e discriminação, família e relacionamentos, por exemplo). A escolha dos temas abordados foi bastante ampla para contemplar, de forma significativa, as diversas faixas etárias presentes no grupo-classe e também as diferentes formações.

Nesse sentido, as atividades sempre se basearam em textos, imagens e vídeos que foram debatidos a partir das questões relacionadas a cada questão das atividades, proporcionando a interação, a motivação e o pensamento crítico. Nessa perspectiva, o interesse dos alunos foi despertado, gerando pesquisas sobre os temas estudados em classe e leituras complementares capazes de estimular a participação dos aprendizes de forma mais significativa nas aulas.

Nas aulas, foram utilizados vídeos, músicas, trechos de filmes e documentários sobre temas cotidianos e temas mais específicos, o que contribuiu também para o envolvimento dos aprendizes e para o desenvolvimento nas aulas, já que todos sempre deviam estar em duplas ou grupos para estarem sempre em comunicação e ajudando uns aos outros. Os aprendizes também interagiram em grupos nas redes sociais, compartilhando informações relacionadas aos temas das aulas, curiosidades sobre a língua estrangeira e prestando suporte mútuo, para que todos pudessem desfrutar do conhecimento igualmente.

Percebeu-se, no decorrer das aulas, que os estudantes tomaram consciência da importância da aprendizagem de uma língua estrangeira para o exercício da cidadania, de forma que puderam reconhecer seus lugares como indivíduos no mundo ao se sentirem inclusos socialmente. Ao interagirem, discutindo os temas, conseguiram mobilizar as quatro habilidades linguísticas para se comunicarem efetivamente de acordo com o nível de proficiência das turmas. As discussões desenvolvidas em sala de aula, através de textos orais e escritos de diversos gêneros, contribuíram para a formação crítico-reflexiva dos estudantes, de modo que eles passaram a questionar as suas crenças e visões de mundo 
como também o contexto externo, sendo ele global ou a comunidade a que cada um pertence.

Nesse contexto, observou-se que os aprendizes fizeram o uso de diversos tópicos discutidos em sala de aula ao utilizá-los em suas produções, bem como demonstraram ter consciência das diferenças e semelhanças, ressignificando seus comportamentos e atitudes no âmbito do uso da língua inglesa. Além disso, notou-se também que os aprendentes desenvolveram as demais competências que fazem parte da metodologia do Programa Portal.

Esse trabalho é considerado importante na vida dos estudantes, visto que os depoimentos da comunidade atendida nos cursos de língua estrangeira demonstram que o curso tem sido percebido como modificador de suas realidades e como uma porta para a universidade.

Com todos esses resultados, os aprendizes se sentiram mais confiantes em ler, escrever e falar em língua inglesa. Muitos deles verbalizaram o interesse em aprender a língua para fins de viagens e para conhecer novas realidades. Outros demonstraram o interesse para fins profissionais e até mesmo para realização de intercâmbios em outros países.

\section{CONSIDERAÇÕES FINAIS}

Buscamos expor neste artigo um relato de experiência sobre o desenvolvimento das atividades do Programa Portal e a forma como ele contribui para o desenvolvimento social e a inclusão, a partir do ensino de língua inglesa. Todo o referencial teórico abordado neste estudo foi de grande importância para estruturar nossa metodologia e fazer com que o trabalho fosse realizado com embasamento.

A necessidade de refletir sobre o trabalho docente no ensino de línguas vai muito além de formar um aprendiz capaz de dominar as competências. A língua enquanto veículo ideológico irá proporcionar que esse indivíduo interaja, viva novas realidades, aprenda com as diferenças e consiga pensar criticamente sobre temas pertinentes para a vida humana. As atividades voltadas para a inclusão fazem com que o indivíduo reflita sobre sua história, amplie suas perspectivas e perceba como as tecnologias de informação têm tornado o mundo mais dinâmico. Isso proporcionará a interação com outras referências culturais, oportunidades educacionais e de inserção social.

A missão ética dos projetos de extensão na Universidade representa o compromisso permanente de contribuir para transformar a sociedade através do diálogo enriquecedor entre a academia e a comunidade. Podemos considerar satisfatórios os resultados alcançados tanto na esfera da aprendizagem de língua estrangeira, pelos alunos matriculados nos cursos de língua inglesa, quanto na formação dos bolsistas, que puderam vivenciar a experiência profissional como professores de língua com uma orientação especializada e consequente desenvolvimento de sua prática docente, ainda incipiente. $\mathrm{O}$ Programa Portal tem representado um espaço real de crescimento pessoal na medida em que contribui para ressignificar representações, comportamentos e atitudes frente ao outro e frente à diferença materializada certamente pela língua-cultura estrangeira, 
vivenciada intensamente nas próprias interações em classe. Os desafios futuros são a ampliação do programa para turmas de nível intermediário e elevação da quantidade de bolsistas nos semestres vindouros.

\section{REFERÊNCIAS}

CANALE, M. From communicative competence to communicative language pedagogy. In: Jack C. Richards \& Richard W. Schmidt. (Eds.), Language and communication. London: Longman, 1983.

CANALE, M.; SWAIN M. Theoretical bases of communicative approaches to second language teaching and testing. Applied Linguistics, n. 1, p. 1-47, 1980.

CELCE-MURCIA, M. Rethinking the role of communicative competence in language teaching. In: Alcón Soler, E.; Safont Jordà, M. P. (Ed.). Intercultural language use and language learning. Netherlands: Springer. p. 41-57. 2007.

CHOMSKY, N. Aspects of the theory of syntax. MIT Press. Massachusetts Institute of Technology, 1965.

HYMES, D. H. On communicative competence. In J. Pride and J. Holmes (Eds.), Sociolinguistics. Penguin, 1972. (Excerpt from the paper published 1971, Philadelphia, University of Pennsylvania Press.)

HYMES, D. H. On Communicative Competence. In: WILKINS, D, A. Notional Syllabuses. Oxford: Oxford University Press, 1976.

JOHNSON, D.W., JOHNSON, R.T., HOLUBEC, E. J., \& ROY, P. Circles of Learning: Cooperative in the classroom. Alexandria, VA: Association for Supervision and Curriculum Development, 1984.

Kleiman, A. Leitura, ensino e pesquisa. 2. ed. Campinas: Pontes, 2001.

LEE, W.Y. Authenticity revisited: Text authenticity and learner authenticity. ELT Journal, v. 49, n. 4, p. 324, 1995.

NÚCLEO DE ASSESSORIA PEDAGÓGICA DA UNIVERSIDADE DO PARANÁ. Uma Breve Introdução ao Letramento crítico na Educação Em Linguas Estrangeiras. - 2006. Disponível em: <https://pt.scribd.com/document/7965991/letramento-critico > Acesso em: 18 dez. 2016.

ORTIZ ALVAREZ, M. L. Uma (Re)definição das Competências do Professor de LE. In: ORTIZ ALVAREZ, M. L. (Org.). Ecos do Profissional de Linguas: competências e teorias. Campinas: Pontes, 2015, p. 235-260.

PCN DE LÍNGUA ESTRANGEIRA - TERCEIRO E QUARTO CICLOS DO ENSINO FUNDAMENTAL - Ministério da Educação - 1998. Disponível em: 
<http://portal.mec.gov.br/seb/arquivos/pdf/pcn_estrangeira.pdf>. Acesso em: 15 dez. 2016.

SAUSSURE, Ferdinand. Curso de linguística geral. São Paulo: Cultrix, p.18, 1969.

SCHUBERT, Bianca P. B. A autenticidade do material didático para o ensino de inglês com língua estrangeira, Linguagens e Diálogos, v. 1, n. 2, p. 18-33, 2010.

SOARES, Magda Becker, (1998). Letramento: um tema em três gêneros. Belo Horizonte: Autêntica.

Recebido em: 05/06/2017

Aprovado em: 23/07/2017

Publicado em: 01/02/2018 